\title{
PENERAPAN PRINSIP BIOPHILIC DESIGN PADA PERANCANGAN APARTEMEN SOHO DI KOTA PEKANBARU
}

\author{
Mahya Fiddini Kaffah ${ }^{1}$, Yohannes Firzal ${ }^{2}$, Mira Dharma Susilawaty ${ }^{3}$ \\ ${ }^{1}$ Jurusan Arsitektur, Fakultas Teknik, Universitas Riau, \\ Kampus Binawidya JI. HR. Soebrantas KM 12.5, Pekanbaru, E-mail: mahya.fiddini3891@student.unri.ac.id \\ 2 Jurusan Arsitektur, Fakultas Teknik, Universitas Riau, \\ Kampus Binawidya JI. HR. Soebrantas KM 12.5, Pekanbaru \\ 3 Jurusan Arsitektur, Fakultas Teknik, Universitas Riau, \\ Kampus Binawidya JI. HR. Soebrantas KM 12.5, Pekanbaru
}

\begin{abstract}
The mobile lifestyle among entrepreneurs in Pekanbaru City presents the need for a place to stay that can be used as an office for work. To meet these needs, the concept of SOHO (Small Office Home Office) can be applied to the apartment. Architecture as a space for human activity is also instrumental in increasing human productivity, so it needs to be considered aspects of the physical environment of a workspace, both in terms of layout and comfort. The biophilic design is applied in the design object because it is able to provide comfort to human physique, improve health, fitness, and well-being of human. Therefore, design of SOHO apartment with the application of biophilic design to create an apartment that not only fulfill the need for residence and place of work but also able to align the interests of humans and nature.
\end{abstract}

Keywords: Biophilic design, Apartment, SOHO

\begin{abstract}
Abstrak
Gaya hidup mobile kalangan pengusaha di Kota Pekanbaru menghadirkan kebutuhan tempat tinggal yang sekaligus dapat dijadikan kantor untuk bekerja. Untuk memenuhi kebutuhan tersebut, maka konsep SOHO (Small Office Home Office) dapat diterapkan pada apartemen. Arsitektur sebagai ruang gerak aktivitas manusia turut berperan dalam peningkatan produktivitas manusia sehingga perlu diperhatikan aspek physical environment dari sebuah ruang kerja, baik dalam segi tata letak maupun kenyamanannya. Pendekatan biophilic design diterapkan dalam objek rancangan karena mampu memberikan kenyamanan bagi fisik manusia, meningkatkan kesehatan, kebugaran, dan kesejahteraan umum manusia. Oleh karena itu, rancangan apartemen $\mathrm{SOHO}$ dengan penerapan biophilic design untuk menciptakan apartemen yang tidak hanya memenuhi kebutuhan sebagai tempat tinggal dan tempat bekerja tapi juga mampu menyelaraskan kepentingan manusia dan alam.
\end{abstract}

\section{Kata kunci: Biophilic design, Apartemen, SOHO \\ 1. Pendahuluan}

Pada era modern saat ini, kehidupan masyarakat kota terus dihadapkan dengan berbagai ancaman akibat polusi, tekanan pekerjaan, hingga gaya hidup yang serba mudah dan tidak sehat. Perkembangan urbanisasi yang cepat menghasilkan lingkungan yang padat penduduk dan didominasi oleh bangunan dan infrastruktur. Interaksi masyarakat kota dengan lingkungan semakin sedikit dan masyarakat menghabiskan sebagian besar aktivitas keseharian di dalam ruangan. Hal itu membuat manusia menjadi kurang terhubung dengan alam. Adanya ikatan dengan alam merupakan kebutuhan manusia, karena pada dasarnya manusia selalu bergantung langsung pada alam untuk kelangsungan hidupnya. Maka dari itu terbentuklah istilah biophilia, yang menyatakan bahwa manusia akan lebih sehat dalam lingkungan alam secara fisik maupun psikologi (Sontarigan, 2017).

Adapun permasalahan pada penerapan prinsip Biophilic Design dalam perancangan apartemen SOHO Di Kota Pekanbaru adalah sebagai berikut:

1. Bagaimana sistem tata ruang yang dapat mewadahi kegiatan berhuni dan bekerja di dalam apartemen SOHO?

2. Apa saja prinsip-prinsip Biophilic Design yang dapat diterapkan pada bangunan apartemen SOHO di Kota Pekanbaru? 
3. Bagaimana menghasilkan konsep desain yang sesuai dengan prinsip Biophilic Design?

\section{Tinjauan Pustaka}

Terdapat kriteria bangunan yang dapat menimbulkan efek restoratif berupa mempercepat tingkat penyembuhan, meningkatkan suasana hati yang baik, dan mengurangi stres bagi penghuninya, yaitu bangunan yang dirancang dengan menghubungkan langsung bangunan dengan alam, yang dikenal dengan biophilic design (Browning, 2012). Biophilic design dapat diterapkan pada berbagai jenis fungsi bangunan, salah satunya yaitu apartemen. Apartemen SOHO merupakan sebuah konsep apartemen yang menempatkan kegiatan kantor secara fisik pada ruang hunian. Kantor yang sifatnya sosial dan cenderung terbuka untuk publik memerlukan setting untuk mewadahi aktivitasnya, kemudian diterapkan pada ruang hunian yang lebih bersifat privat (Hendrawan, 2016). Semakin banyak profesi yang cocok dengan konsep SOHO, yaitu profesi yang tidak terlalu menuntut jam kerja tetap dan berada di belakang meja setiap saat (fleksibel). Seperti profesi yang bergerak dibidang kreatif, arsitek, desainer, grafis, penulis, fotografer, koki, pemusik, dan masih ada segudang profesi kreatif lainnya yang tumbuh makin marak dalam kurun 5 tahun terakhir (Akmal, 2010). Laju pertumbuhan kategori jasa perusahaan pada tahun 2018 merupakan laju pertumbuhan tertinggi di Kota Pekanbaru yaitu sebesar 10,11\% (BPS Kota Pekanbaru, 2018). Sedangkan kategori real estat pada tahun 2018, laju pertumbuhan ekonominya lebih meningkat dari tahun sebelumnya yaitu sebesar 3,43\%. Maka apartemen $\mathrm{SOHO}$ memiliki prospek yang baik di Pekanbaru karena didukung oleh perkembangan lapangan usaha di bidang jasa perusahaan dan real estat yang semakin meningkat (tabel 1).

Tabel 1. Laju pertumbuhan PDRB Kota Pekanbaru tahun 2016-2018

(Sumber : BPS Kota Pekanbaru, 2018)

\begin{tabular}{|l|c|c|c|}
\hline $\begin{array}{l}\text { Lapangan Usaha / } \\
\text { Industry }\end{array}$ & 2016 & 2017 & 2018 \\
\hline $\begin{array}{l}\text { Real Estat/Real } \\
\text { Estate }\end{array}$ & $1.87 \%$ & $2.34 \%$ & $3,43 \%$ \\
\hline $\begin{array}{l}\text { Jasa Perusahaan/ } \\
\text { Business } \\
\text { Activities }\end{array}$ & $3,41 \%$ & $8.73 \%$ & $10,11 \%$ \\
\hline
\end{tabular}

\section{Metode}

Strategi perancangan pada apartemen $\mathrm{SOHO}$ melalui beberapa tahapan dimulai dari analisis fungsi, analisis tapak, analisis ruang, konsep perancangan, zoning, bentukan massa, tatanan ruang dalam, sirkulasi, lansekap, analisis struktur, dan utilitas hingga mendapatkan hasil perancangan.

Metode pengumpulan data terbagi menjadi dua jenis, yaitu data primer dan data sekunder. Data primer diperoleh melalui pengamatan mengenai hal-hal penting terhadap objek perancangan serta pengamatan terhadap masalah-masalah yang ada secara langsung. Data sekunder bersumber dari media perantara atau secara tidak langsung yang berupa buku, catatan, bukti yang telah ada, atau arsip baik yang dipublikasikan maupun yang tidak dipublikasikan secara umum.

\section{Analisis}

Lokasi tapak berada di Jl. Sudirman, Kel. Tangkerang Tengah, Kec. Marpoyan Damai, Kota Pekanbaru, dengan data fisik sebagai berikut:

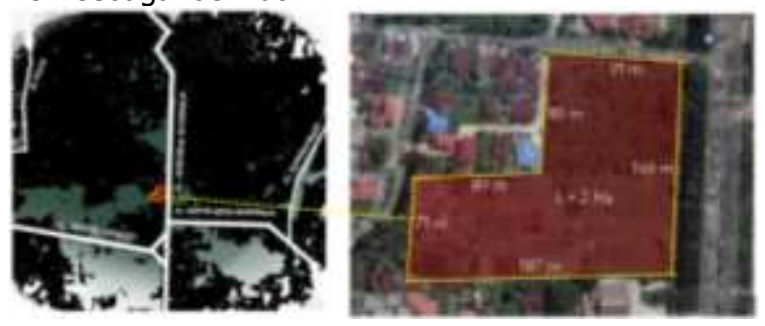

Gambar 1. Lokasi site

Sumber : Google Maps 
Jurnal Arsitektur AIUR - Vol 3 No 1 Mei 2020

e-ISSN 2685-1490; p-ISSN 2615-1472

Lokasi ini berbatasan dengan Jl. Letkol Syariefuddin Syarief di sisi utara, Teras Kayu Resto di sisi selatan, Jl. Jenderal Sudirman di sisi timur, dan permukiman warga di sisi barat. Dalam menentukan besaran ruang dalam apartemen $\mathrm{SOHO}$ memerlukan sejumlah pertimbangan, antara lain pola dan macam kegiatan yang menghasilkan tuntutan kebutuhan ruang.

Tabel 2. Luas Kebutuhan Ruang dalam Apartemen SOHO

\begin{tabular}{|l|c|}
\hline \multicolumn{1}{|c|}{ Fasilitas } & Luas \\
\hline SOHO & $30.507,27 \mathrm{~m}^{2}$ \\
\hline Penunjang & $1.715,13 \mathrm{~m}^{2}$ \\
\hline Umum & $5.207 \mathrm{~m}^{2}$ \\
\hline Pengelola & $426,69 \mathrm{~m}^{2}$ \\
\hline Service & $351,12 \mathrm{~m}^{2}$ \\
\hline Total keseluruhan & $38.207,21 \mathrm{~m}^{2}$ \\
\hline
\end{tabular}

Zoning dalam tapak terbagi menjadi zona fasilitas hunian, zona fasilitas penunjang, zona fasilitas pengelola, zona fasilitas umum, zona fasilitas service, dan zona taman.

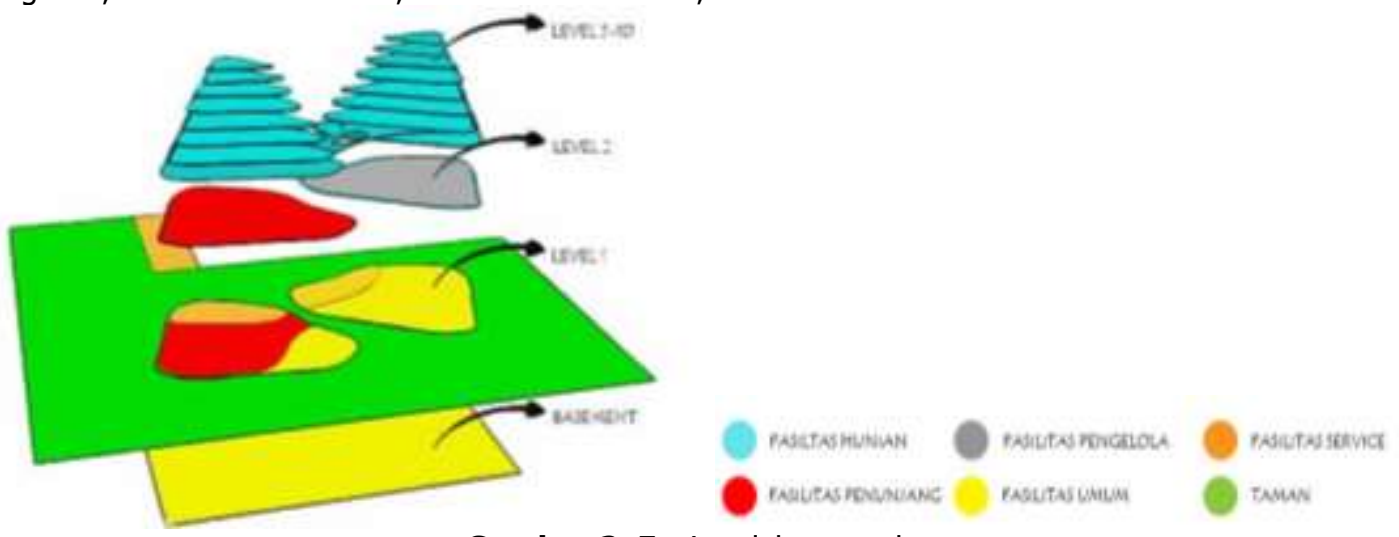

Gambar 2. Zoning dalam tapak

\subsection{Konsep}

Konsep yang diterapkan pada apartemen SOHO di Kota Pekanbaru adalah the Living Hills. Konsep ini sesuai dengan prinsip Biophilic Design yaitu biomorphic forms and patterns (bentuk dan pola biomorfik) dan complexity and order (kompleksitas dan keteraturan).

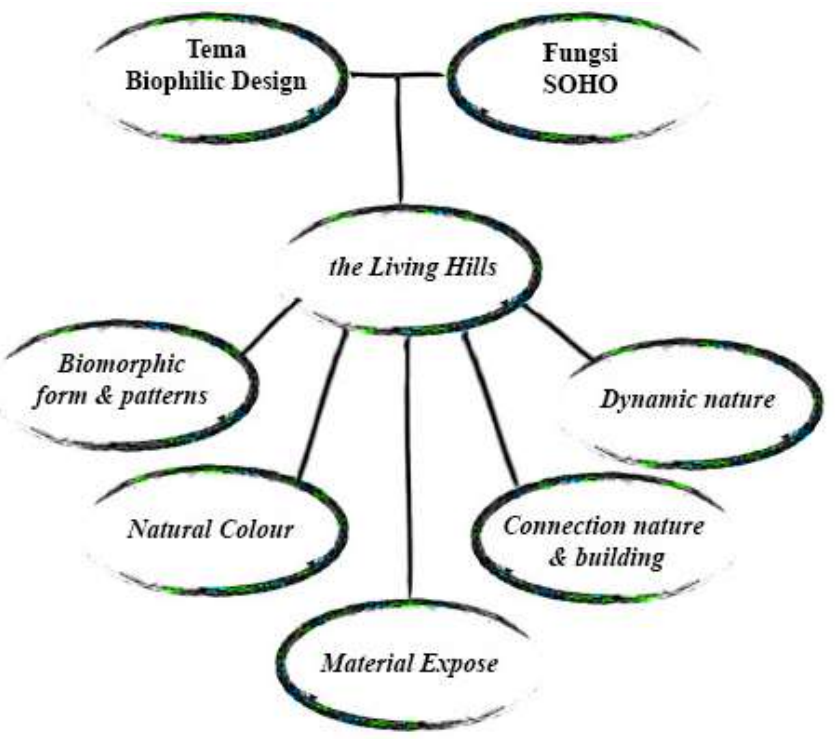

Gambar 3. Konsep Dasar Desain 


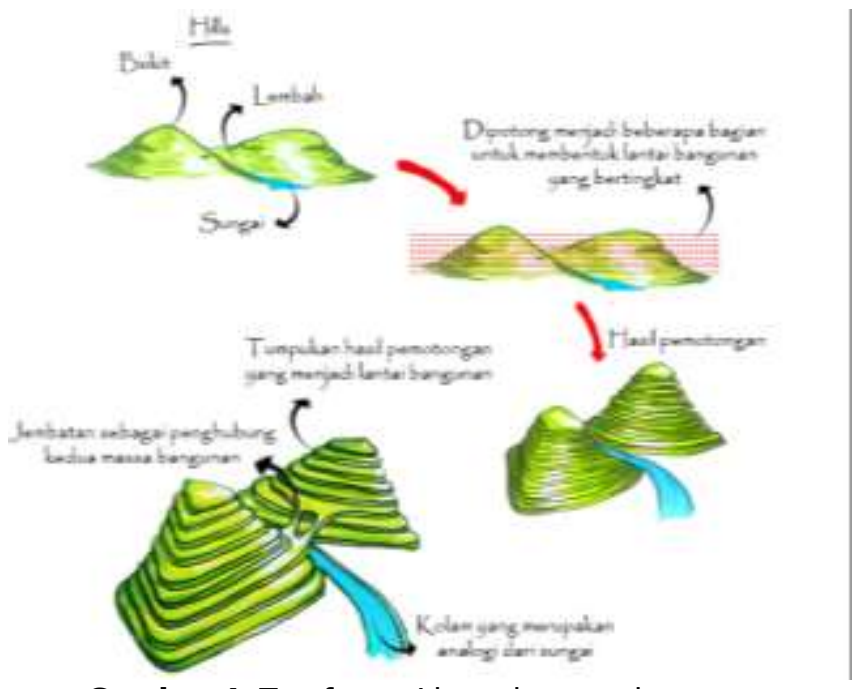

Gambar 4. Tranformasi bentuk massa bangunan

Lantai bangunan yang terlihat seperti tumpukan layer yang berlika-liku menyerupai kontur tanah perbukitan menggambarkan bahwa untuk mencapai puncak harus melalui proses yang tidak mudah, sama halnya dengan dunia kerja yang harus melewati berbagai proses sulit untuk sampai pada tujuan yang ingin dicapai. Unit hunian yang letaknya berada di level paling atas merupakan unit hunian yang memiliki ruang paling luas dan fasilitas yang paling lengkap, hal itu sebagai simbol dari kesuksesan yang telah diperoleh oleh penghuni unit apartemen SOHO. Setiap hunian memiliki ruang terbuka hijau yang tampak pada area balkon. Fasad bangunan juga menggunakan green wall dan vegetasi merambat. Oleh karena banyaknya vegetasi tersebut, eksterior apartemen SOHO menjadi tampak hijau dan sejuk seperti sebuah bukit.

\subsection{Penerapan Tema}

Perancangan apartemen SOHO ini menerapkan tema berdasarkan prinsip-prinsip Biophilic Design yang dijelaskan sebagai berikut.

Tabel 4. Prinsip biophilic design dan penerapannya pada objek rancangan

\begin{tabular}{|c|l|l|}
\hline No & \multicolumn{1}{|c|}{ Prinsip Biophilic Design } & \multicolumn{1}{c|}{ Penerapan } \\
\hline 1 & Koneksi visual dengan alam & $\begin{array}{l}\text { Green wall, kolam, akuarium, vegetated roof, dan } \\
\text { taman. }\end{array}$ \\
\hline 2 & Koneksi non-visual dengan alam & $\begin{array}{l}\text { Wewangian dari tanaman, ventilasi alami, dan simulasi } \\
\text { digital suara alam. }\end{array}$ \\
\hline 3 & Stimuli non-ritmik & $\begin{array}{l}\text { Warna-warna yang memberikan kesegaran, bentuk- } \\
\text { bentuk organik, dan penataan tanaman menarik. }\end{array}$ \\
\hline 4 & Thermal dan variasi aliran udara & $\begin{array}{l}\text { Pencahayaan alami, ventilasi silang, dan mengatur } \\
\text { orientasi serta bukaan pada bangunan. }\end{array}$ \\
\hline 5 & Air & $\begin{array}{l}\text { Water wall, kolam, dan akses visual terhadap air } \\
\text { hujan. }\end{array}$ \\
\hline 6 & Cahaya dinamis dan menyebar & Pencahayaan alami dan buatan (lampu). \\
\hline 7 & Bentuk dan pola biomorfik & Peniruan bentuk alam. \\
\hline 9 & Koneksi material dengan alam & Material alami atau yang menyerupai material alami. \\
\hline 10 & Kompleksitas dan keteraturan & $\begin{array}{l}\text { Mengekspos struktur dan bahan, desain dinding dan } \\
\text { pola lantai yang menarik. }\end{array}$ \\
\hline 11 & Koneksi antar sistem alami & $\begin{array}{l}\text { Mengintegrasikan penangkap air hujan dengan sistem } \\
\text { pengolahan air. }\end{array}$ \\
\hline 12 & Refuge & $\begin{array}{l}\text { Mengatur orientasi bangunan, perletakkan koridor dan } \\
\text { balkon, memaksimalkan view. }\end{array}$ \\
\hline 13 & Misteri & $\begin{array}{l}\text { Area privat dengan plafon yang rendah. } \\
\text { Koridor melengkung dan jalan setapak pada taman } \\
\text { yang ditumbuhi pepohonan tinggi. }\end{array}$ \\
\hline
\end{tabular}


Jurnal Arsitektur ALUR - Vol 3 No 1 Mei 2020

e-ISSN 2685-1490; p-ISSN 2615-1472

\begin{tabular}{|l|l|l|}
\hline 14 & Resiko & Architectural cantilever dan railing transparan. \\
\hline
\end{tabular}

\subsection{Fasad}

Secondary skin dan green wall digunakan pada bagian timur dan barat bangunan agar dapat mereduksi paparan sinar matahari langsung yang berlebih. Selain itu penggunaan banyak tumbuhan sebagai bagian dari selubung bangunan juga merupakan salah satu unsur dari prinsip biophilic design.

Secondary skin kayu digunakan karena orientasi bangunan menghadap ke barat. Kayu berfungsi untuk mereduksi paparan cahaya matahari yang menerpa bangunan secara berlebih. Selain itu, secondary skin berbahan kayu juga berpengaruh terhadap estetika fasad.

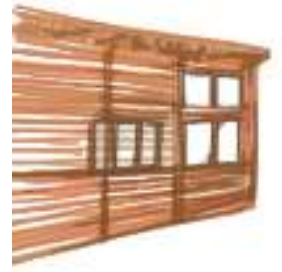

Gambar 5. Secondary Skin Kayu

Apartemen $\mathrm{SOHO}$ ini juga menggunakan green wall sebagai fasad. Green wall sistem tanam yang menyerupai dinding, meliputi media tanam, struktur dan sistem irigasi, dikenal sebagai living walls, biowalls, ecowalls, dan vertical garden.

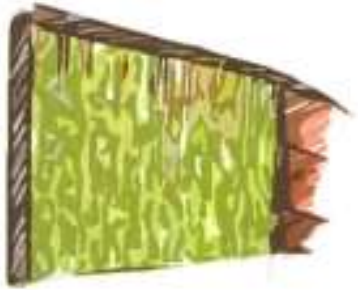

\subsection{Interior}

Gambar 6. Green wall

Interior bangunan dirancang mampu menstimulasi ingatan pengguna ruang akan lingkungan alam. Interior apartemen $\mathrm{SOHO}$ memanfaatkan unsur alam dengan menggunakan taman dalam ruang, green wall, gambar atau lukisan alam, kolam, water wall, akuarium, dekorasi air mancur, dan elemen interior yang terbuat dari material alami. Suasana alam dapat sangat dirasakan dengan bayangan yang dihasilkan oleh pergerakan awan, adanya gerakan tanaman yang tertiup angin, refleksi air, dan aroma yang berasal dari tanaman di dalam ruangan.

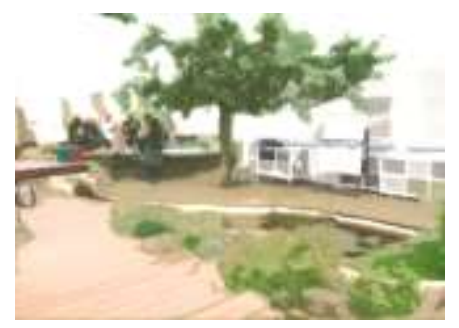

Gambar 7. Interior dengan prinsip biophilic design

Suara alam seperti suara burung yang dihasilkan dari audio speaker. Penggunaan material alami kasar diterapkan untuk memberikan koneksi indra peraba dengan alam. Pada elemen pengisi interior diterapkan pola-pola yang memiliki bentuk atau motif menyerupai bentuk alam, skylight, dinding kaca, dan jendela sebagai akses cahaya matahari agar terlihat pergerakan atau perubahan cahaya matahari sehingga pengguna ruang dapat merasakan adanya perubahan waktu atau cuaca meskipun sedang berada di dalam bangunan. 


\subsection{Konsep Tapak}

Tapak dibagi menjadi 5 zona, yaitu zona bangunan, zona sirkulasi kendaraan, zona taman, dan zona kolam.

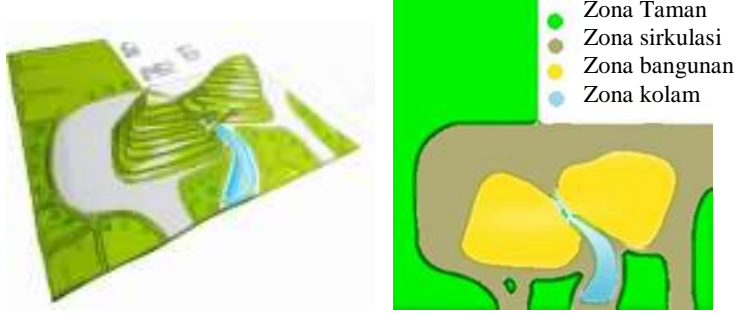

Gambar 8. Pembagian zona pada tapak

Prinsip biophilic design pada tapak ditunjukkan dengan banyaknya tanaman peneduh. Pada zona taman terdapat berbagai jenis vegetasi untuk mengundang datangnya serangga. Kolam dengan air mancur juga dihadirkan untuk memasukkan unsur air. Taman tersebut diisi bangku-bangku untuk mewadahi kegiatan interaksi sosial antar pengunjung apartemen atau interaksi dengan alam.

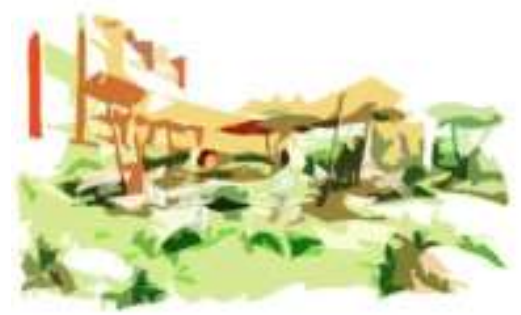

Gambar 9. Taman sebagai ruang berinteraksi sosial

Pola lansekap ditata membentuk pola yang dinamis, dibuat berkontur untuk menyesuaikan konsep the Living Hills. Permukaan lansekap tersebut memiliki level yang berbeda-beda, dapat diciptakan dengan penataan vegetasi yang memiliki tinggi yang berbeda-beda, jalan yang dibuat sedikit menanjak atau menurun, dan membuat terasering yang dapat dimanfaatkan sebagai tangga.

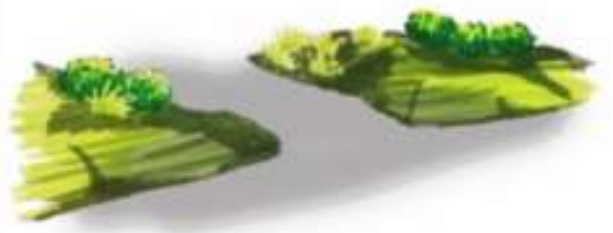

Gambar 10. Kontur pada taman



Gambar 11. Tangga pada lansekap

\subsection{Konsep Sirkulasi dan Parkir}

Pola sirkulasi yang diterapkan yaitu pola sirkulasi 1 arah. Pengunjung dapat menuju drop-off terlebih dahulu kemudian memarkirkan kendaraan atau langsung menuju tempat parkir yang berada di basement apartemen SOHO. Entrance berada di Jl. Jenderal Sudirman langsung mengarahkan ke area parkir dan keluar lagi melalui Jl. Jenderal Sudirman. 
Jurnal Arsitektur AIJR - Vol 3 No 1 Mei 2020

e-ISSN 2685-1490; p-ISSN 2615-1472

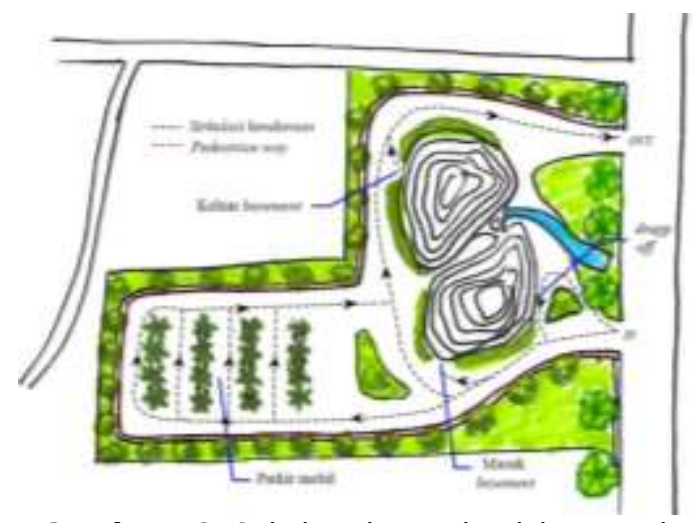

Gambar 12. Sirkulasi dan parkir dalam tapak

\subsection{Vegetasi}

Vegetasi pada tapak mempunyai fungsi sebagai peneduh, pengarah, penyaring polusi, penghias, dan untuk mengurangi kebisingan. Selain pada area lansekap, vegetasi juga terdapat pada fasad bangunan yang berfungsi sebagai greenwall.

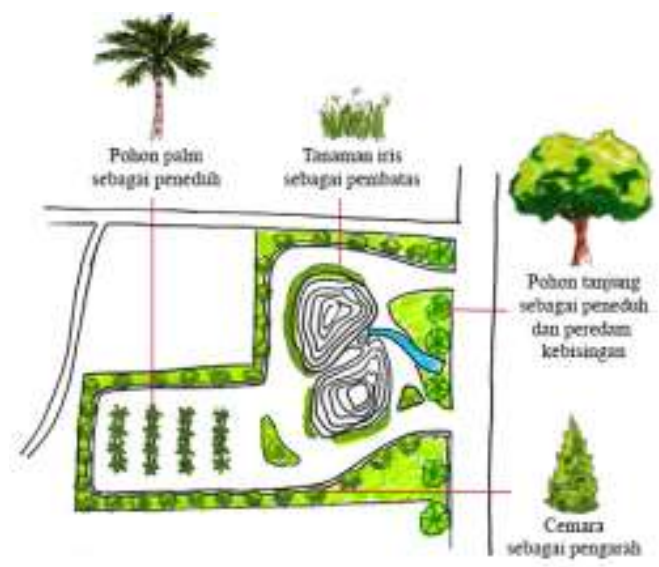

Gambar 13. Penataan vegetasi pada tapak

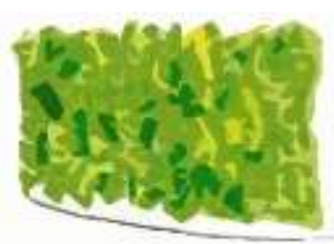

Gambar 14. Tanaman rambat pada fasad bangunan

\section{Kesimpulan dan Saran}

\section{Kesimpulan}

Dari Penerapan Prinsip Biophilic Design pada Perancangan Apartemen SOHO di Pekanbaru ini maka dapat disimpulkan bahwa :

1. Prinsip-prinsip biophilic design dinilai dapat meningkatkan kesehatan psikologis individu sehingga sangat cocok jika diterapkan pada apartemen $\mathrm{SOHO}$ dengan ruang kerja yang nyaman untuk meningkatkan produktivitas.

2. Perancangan apartemen SOHO di Pekanbaru bertujuan untuk mewadahi kebutuhan sebuah hunian sekaligus ruang kerja. 
3. Dengan tema dan fungsi yang memiliki keterkaitan, maka konsep the Living Hills diekspresikan melalui bentukan massa yang berasal dari alam, penggunaan warna natural, material yang diekspos, menghubungkan lingkungan alam dengan bangunan, dan memasukkan unsur alam yang dinamis.

\section{Saran}

Dalam perancangan apartemen SOHO diharapkan memperhatikan fasilitas fungsi apartemen SOHO dengan baik agar memenuhi kebutuhan akan ruangan yang sesuai. Tema yang diterapkan dalam bangunan juga perlu memiliki keterkaitan dengan fungsi agar dapat mencapai hasil perancangan yang maksimal.

\section{Daftar Pustaka}

Akmal, Imelda. SOHO : Small Office Home Office. Jakarta: Gramedia, 2010.

Azalea, Amy. Small Office Home Office [online], 2017.

Badan Pusat Statistik Kota Pekanbaru. Produk Domestik Bruto Kota Pekanbaru, 2019.

Browning,W., Ryan C., dan Clancy J. 14 Patterns of Biophilic Design. Terrapin Bright Green, LLC, 2014.

De Chiara. Joseph, dan John Calender. Time Saver Standart for Building Types. New York : Mcgraw Hill Book Company, 1984.

Hendrawan, T. Kajian Pola Kontrol Privasi Penghuni terhadap Penerapan Konsep SOHO (Small Office Home Office) pada Rumah Tinggal di Kota Bandung. Serat Rupa Journal of Design, Vol.1, No.1 (2018):100-114.

J. Priatman, "Konsep Desain Biophilia Sebagai Dimensi Hijau pada Arsitektur Empatik," dalam Seminar Nasional Menuju Arsitektur berEmpati Surabaya: Universitas Kristen Petra (2012) 38-39.

Kaplan, R.M., Sallis, J.M., Patterson, T.L. Health and Human Behaviour. New York: Mc. Graw Hill Inc, 2001.

Kellert, Stephen R. Building for Life : Designing and Understanding the Human-Nature Connection, 2005.

Lynch, Kevin and Hack, Gary.Site Planning, $3^{\text {rd }}$ edition, Cambridge: The MI. Press, 1984.

Neufert, Ernst. Data Arsitek Jilid 1. Jakarta : Erlangga, 1996.

Neufert, Ernst. Data Arsitek Jilid 2. Jakarta : Erlangga, 2002.

Paul, Samuel. Apartments, Their Design \& Development. NewYork : Rainhold, 1976.

Poerwadarminta,W.J.S.1991. Kamus Umum Bahasa Indonesia. Balai Pustaka. Jakarta.

Rippen,Kenneth H . Office Space Administration. Me Graw-Hill Book Company, 1974.

Sadikin, Ali . Peraturan Tari (Sewa Ruang Perkantoran Di DKJ Jakarta, Surat Keputusan Gubemur DKI, Jakarta No 208/Tahun 1977, 1977.

Savitri, E., Ignatius, M., Budihardjo, A., Anwar, I., Rahwidyasa, V. Indonesian Apartment: Design Concept Lifestyle. Jakarta: PT. Griya Asri Prima, 2007.

S. R. Kellert, J. H. Heerwagen, and M. L. Mador. Biophilic Design:The Theory, Science and Practice of Bringing Buildings to Life.New Jersey: John Wiley \& Sons, 2008.

Sontarigan, F. Panduan Desain Arsitektur dengan Pendekatan Biophilic Design pada Bangunan Perkantoran, 2017.

Undang-Undang No.16 tahun 1985 tentang Rumah Susun. 